\title{
Os modos de suscitação e a escolha dos representativos da controvérsia no microssistema de formação de precedentes vinculantes
}

\author{
Evocation modes and the choice of representative of controversy in the microsystem of \\ formation of binding precedents
}

Vinicius Silva Lemos' Rennan Thamay ${ }^{2}$

${ }^{1}$ FARO e UNIRON, Brasil ${ }^{2}$ FADISP, Brasil

\section{Resumo}

Este artigo tem o propósito de analisar os processos ou recursos representativos da controvérsia no microssistema de precedentes vinculantes imposto pelo CPC/2015, desde os modos de suscitação de cada instituto até o processo de escolha desse representativo da controvérsia, delineando o diálogo com todos os institutos formadores de precedentes vinculantes.

Palavras-chave: Precedentes Vinculantes. Representativos da Controvérsia. Suscitação. Escolha.

\begin{abstract}
This article has the purpose to analyze the processes or resources representative of controversy in the microsystem binding precedents imposed by the $C P C / 2015$, since the modes of evocation of each institute until the process of choice of representative of controversy, outlining the dialog with all institutes former of binding precedents.
\end{abstract}

Keywords: Binding Precedents. Representative of Controversy. Evocation. Choice.

\section{Introdução}

O CPC/2015 trouxe uma nova realidade processual para todo o cotidiano jurídico, com novos dogmas e delineando realidades propositivas, como um microssistema de decisões vinculantes, os chamados precedentes judiciais vinculantes.

Todos esses precedentes que detêm vinculação passam por ritos incidentais para uma tramitação diferenciada e a devida formação de um precedente, utilizando uma técnica de julgamento por amostragem, com o julgamento de uma ou algumas demandas e impacto nos demais processos que guardam identidade fático jurídica.

Se esses precedentes são formados a partir de processos base, com a análise específica destes para a formação de uma norma jurídica abstrata de aplicabilidade em demandas existentes ou vindouras, estes processos tidos como base devem ser escolhidos para representarem a controvérsia que será sanada e formado o precedente judicial vinculante, 
O processo de suscitação de cada instituto e seu modus operandi, bem como os meios de escolha dos processos ou recursos representativos da controvérsia é o objeto desse estudo, com o intuito de através dessa pesquisa, delinear os critérios de fixação de escolha destes processos ou recursos e o devido entendimento e importância dessa escolha.

\section{O microssistema de formação de precedentes vinculantes}

A norma processual, nos últimos anos ${ }^{1}$, busca soluções tanto para o excesso de demandas existentes no Judiciário, principalmente em direitos individuais homogêneos, quanto para a instabilidade jurídica e, consequentemente, isso resulta em inovações criativas de institutos que visam analisar menos casos, com uma ênfase e impacto nos demais, seja para julgar em massa ou conceder repercussão geral ou para dar efetividade a isonomia jurídica, utilizando como base o brocardo "treat like cases alike", utilizado por Cross e Harris para designar que a resolução dos conflitos deve ser igual para casos isonômicos.

O intuito a longo prazo será proporcionar aos Tribunais, principalmente os superiores, a julgar menos processos, com a utilização destes como base para as outras demandas idênticas. Para tanto, no CPC/2015, foram concedidas a algumas espécies de decisões, um caráter vinculante, geralmente após passar por um procedimento diversificado dos demais.

Não há como entender que num passe de mágica que o ordenamento brasileiro passou para uma adoção de uma teoria de precedentes, contudo foi um importante passo para a mudança cultural judicante para pensar numa teoria da estabilização das decisões judiciais ${ }^{3}$.

Com isso, houve a restauração e oxigenação de institutos como a repercussão geral, o rito repetitivo e a arguição de inconstitucionalidade, somados com a criação do incidente de resolução de demandas repetitivas e a positivação adequado do incidente de assunção de competência, os quais juntos formam um microssistema de formação de precedentes vinculantes, muito maior do que um microssistema de casos repetitivos - que também foi impulsionado legislativamente, mas muito maior, com a preocupação de pensar uma lógica vinculante para os julgamentos dos Tribunais.

Em todos esses institutos buscarem a repercussão do julgamento em demais casos, com vinculações legislativas, com mudança de procedimento, com um rito diversificado e qualificado, no intuito de formar um precedente, ainda que não seja uma construção da forma com que outros países se atem a precedentes.

Diferentemente da forma com que culturalmente nasce um precedente, com a construção em camadas argumentativas até chegar-se na vinculação, já no Brasil, mediante diversos institutos, os quais separamos os cinco que entendemos que formam um microssistema de formação de precedentes vinculantes pela

1 "Essa fase da reforma constitui uma tentativa de solucionar os problemas gerados pela "abertura das portas do Judiciário", que ocasionou um considerável aumento do número de demandas, possuindo, desta forma, o objeto primordial de diminuir o número destes processos em trâmite nos Tribunais brasileiros, efetivando o princípio da celeridade de forma raciona e, consequentemente, reduzir substancialmente com a famigerada morosidade da Justiça Brasileira em concretizar uma resposta final aos anseios dos litigantes processuais” RIBEIRO, Cristiana Hamdar. A lei dos recursos repetitivos e os princípios do direito processual civil brasileiro. Revista Eletrônica de Direito Processual - Volume V, n. 5. 2010 . p. 622 .

2 Livre tradução de: CROSS, Rupert; HARRIS, J. W. Precedent in English Law. 4.ed. Oxford: Oxford University Press, 2004. p. 3.

3 Para Ataíde Jr, ao defender que os sistemas jurídicos devem se adequar à nova realidade de julgamento destas demandas não aplacáveis ao julgamento meramente individual, devem guardar a relação de um rito próprio e diverso com as seguintes características: “(i) a rápida fixação da tese jurídica, a reger o julgamento de todas as causas semelhantes (ii) maior previsibilidade na aplicação do direito; (iii) um julgamento isonômico - para que casos análogos sejam solucionados da mesma maneira (treat like case alike); (iv) criação de filtros processuais, que possibilitem a diminuição do número de recursos nos tribunais superiores e, com isso, a eliminação da divergência jurisprudencial interna, bem como possibilitem a reprodução de maior qualidade e, sobretudo, (v) uma cultura de respeito aos precedentes." ATAÍDE JR, Jaldemiro Rodrigues de. As demandas de massa e o projeto de novo código de processo civil. In FREIRE, Alexandre at. Novas tendências do processo civil. Salvador: Jus Podivm, 2014. p. 48. 
convergência de institutos internos. Para chegarmos a essa construção ${ }^{4}$, levamos em consideração alguns aspectos para delimitar que seria o microssistema de formação de precedentes vinculantes: a decisão de afetação, a possibilidade de sobrestamento das demais demandas idênticas, a necessidade de um contraditório ampliado e a vinculação posterior do posicionamento adotado neste julgamento realizado.

Essas espécies de precedentes vinculantes, cada qual a seu modo peculiar, passam por técnicas para que se julgue uma só demanda - ou um grupo de demandas, com o intuito de que o resultado analítico dessa decisão seja paradigmático ao demais processos que tenham identidade fática material.

Dada a existência de um grande fluxo de demandas no Brasil, gerando um esgotamento da capacidade judicante, não há mais como encarar os litígios individuais no mesmo modus operandi anterior do processo civil brasileiro, como pensado nos CPCs de 1939 e $1973^{5}$. Há, portanto, a necessidade de uma mudança na forma de enquadramento processual à realidade dos Tribunais, uma adaptação sistêmica ${ }^{6}$, como preconiza a própria existência de uma vinculação de decisões para outras demandas, como proposto nesse microssistema delineado no CPC/2015.

\subsection{O processo representativo da controvérsia e a sua importância para a formação do precedente vinculante}

Para a adoção de qualquer dos institutos insertos ao microssistema de formação de precedente, se faz necessária a existência de um ou mais processos para servirem de base para o julgamento que formará o precedente e, consequentemente, firmar a norma jurídica abstrata que terá serventia para casos análogos já existentes ou futuros.

4 Existem outros institutos que o art. 927 considera como vinculantes no novel ordenamento processual, no entanto, consideramos que não fazem parte deste rol do microssistema como as súmulas - vinculantes ou não - ou as decisões em controle concentrado de constitucionalidade. O motivo da não inserção nesse rol são as características abstratas e diversas do que esses institutos, o que não gera a opinião de que não são importantes ou não vinculem, somente não há como conceber que as súmulas sejam precedentes, uma vez que não há um caso em concreto sobre o qual se debruça analiticamente para chegar ao precedente e, sim, a comunhão de vários casos que tendem a um mesmo lado, com aspectos parecidos. "Na verdade, Didier anuncia uma crítica à redação de uma súmula como sendo dirigida à "redação do precedente judicial”. Porém, súmula não é “precedente”. Um precedente é um caso anteriormente apreciado e julgado por um juiz ou Tribunal. Por ser caso, tem nome, sobrenome e individualidade. Efetivamente, as súmulas, sejam "comuns" ou vinculantes, não podem ser consideradas precedentes strico sensu, por várias razões." STRECK, Lênio Luiz. Súmulas, vaguezas e ambiguidades: necessitamos de uma "teoria geral dos precedentes"? Direitos Fundamentais \& Justiça no 5 - out. /DEZ. 2008. p. 164. "Por sua vez, a súmula tem por objetivo veicular o resumo editado, numerado e sintético das teses vencedoras componentes da jurisprudência predominante de um Tribunal sobre uma matéria específica, sobre o qual existiu considerável discussão em algum período histórico, esclarecendo a interpretação vencedora do debate.” CAMBI, Eduardo. FOGAÇA, Mateus Vargas. Sistema dos precedentes judiciais obrigatórios no novo código de processo civil. Precedentes. Organizadores: DIDIER JR., Fredie; CUNHA, Leonardo Carneiro da; MACEDO, Lucas Buril de; ATAIDE JR, Jaldemiro Rodrigues de. Editora JusPodivm, Salvador, 2015. p. 343.Lima explica bem ao dizer que "o elemento sumular, vinculante ou não, não importa de qual tribunal, não é verdadeiramente um precedente judicial.” LIMA, Tiago Asfor Rocha. Precedentes judiciais civis no Brasil. São Paulo, Ed. Saraiva. 2013. p. 197. O motivo pelo qual não inserimos o controle concentrado de controle de constitucionalidade persiste em não ser um processo de caso concreto e, apesar do seu evidente caráter vinculante, existe pelo próprio rito de verificação - seja na ADin, ADCon ou ADPF - para a análise via este rito, o que não proporciona convergência com os outros institutos, como vimos nas hipóteses de proximidades entre estes.

5 “Como parte do problema impõe-se reconhecer que o Código vigente (Lei 5.869/73) fora idealizado sob matizes individualistas. Não fora concebido para solucionar e pacificar litígios coletivos, indivisíveis e transindividuais14, tampouco demandas repetitivas sobre direitos individuais homogêneos.” TEIXEIRA, Guilherme Puchalski. Incidente de resolução de demandas repetitivas: projeções em torno de sua eficiência. Revista eletrônica de direito processual - REDP. Volume 16. Julho a dezembro de 2015. p. 215 .

6 "Não há dúvidas de que as demandas de massa tem características próprias, que as diferem das demandas individuais e coletivas, exigindo dos diversos países a adaptação de seus sistemas jurídicos, a fim de tratá-las mais adequadamente, tendo em vista a insuficiência do regime processual das demandas individuais e coletivas para com as mesmas.” ATAÍDE JR, Jaldemiro Rodrigues de. As demandas de massa e o projeto de novo código de processo civil. In FREIRE, Alexandre at. Novas tendências do processo civil. Salvador: Jus Podivm, 2014. p. 48. 
Esses processos - ou recursos - podem ser vários - como nos recursos excepcionais repetitivos - ou se somente um, dependendo da qualidade do debate inserto naquele processo. Esses serão os chamados recursos representativos da controvérsia.

O processo que servirá de base para a discussão sobre a formação do precedente judicial vindouro deve conter todos os requisitos que aquele instituto necessita, variando a incidência destes para precedente a ser criado.

Se o julgamento é por uma amostra mínima para a aplicabilidade em um todo, posteriormente, pertinente que nessa escolha dos recursos - ou processos - contemple-se o máximo de fundamentos possíveis ou a maior amplitude sobre a matéria. Cada recurso ou processo, mesmo diante de somente um assunto, argumenta-se de diferentes modos, com teorias diversas sobre aqueles fatos ou matéria, com uma gama de fundamentos almejando, por vezes, o mesmo resultado.

Ao relacionar essas alternativas de fundamentação com a atribuição a qualquer instituto de formação de precedente, deve-se selecionar os processos que serão base para esse julgamento com a necessidade de contemplação de todas as teses jurídicas possíveis e visualizáveis daquela questão de direito.

O intuito da representação da controvérsia é ampliar os fundamentos recursais, para esgotar todas as possibilidades jurídicas da questão a ser julgada, de modo a possibilitar ao Tribunal um exaurimento da matéria colocada em questão, para facilitar a adequação posterior dessa decisão para a maior quantidade dos recursos/processos idênticos que estão à espera da definição do julgamento por amostragem.

Se houver um processo que seja coletivo sobre aquela questão, talvez seja melhor que este seja o escolhido para ser julgado, em preferência aos demais individuais, contudo não há previsão legal de que assim seja, somente uma melhor visão cognitiva sobre aquela matéria.

A importância da escolha do representativo da controvérsia é enorme para o debate a ser realizado na formação do precedente, justamente por representar a qualidade das argumentações e conseguir contemplar todos as visões fundamentais sobre aquela matéria. Um precedente formado por um processo com deficit de argumentação ou que não corresponda integralmente à matéria afetada pode gerar um precedente ruim ou sem autoridade argumentativa, o que geraria em pouco tempo a necessidade de revisão de tese.

Quanto melhor o - ou os - processo representativo da controvérsia, melhor a formação do próprio precedente firmado dentro do microssistema de formação de precedente.

\section{O requerimento para a instauração dos institutos do microssistema e o seu devido juízo de admissibilidade}

Qualquer processo tem um procedimento pré-determinado pelo próprio ordenamento processual, com uma série de atos ordenados para a melhor condução processual. Se for na esfera recursal, de igual maneira, com uma tramitação delineada pela ordem dos processos nos Tribunais, quase sempre com distribuição, remessa ao relator, análise deste, preparação do voto, comunicação ao presidente para inclusão na pauta e sessão de julgamento.

No entanto, quando determinado recurso - ou demanda em algumas hipóteses - está com a possibilidade da inserção de uma das técnicas insertas do microssistema mencionado, há ter a modificação do rito, com a possibilidade de julgamento para a formação de um precedente vinculante, com um procedimento diverso dos demais processos que não formarão precedentes.

Para a alteração do seguimento normal da demanda para a transferência procedimental para o rito do microssistema, cada instituto tem o seu próprio método, a sua própria tipificação de requerimento ou de início, com a estipulação legal dos legitimados e o trâmite devido para proceder tal alteração, dando início, para aquela demanda, do rito para a formação do precedente vinculante.

\subsection{Repercussão geral}


Na repercussão geral, o início depende do requerimento do recorrente, uma vez que o próprio instituto é um requisito de admissibilidade, sobre o qual parte, quando for interpor o recurso extraordinário, deve realizar a demonstração ${ }^{7}$ de que a sua causa tem questão transcendental, ensejando, portanto, a análise deste recurso pelo STF.

Não há como um recurso extraordinário ser analisado sem o cumprimento desse ponto recursal, o que impõe que a demonstração da repercussão geral é ato da parte, inerente à própria existência da repercussão geral e, consequentemente, do recurso extraordinário.

A consequência dessa imposição da inserção no bojo do próprio recurso extraordinário da demonstração da repercussão geral atinge também a análise do próprio instituto pelo juízo ao receber o recurso, devendo analisar a sua admissibilidade - outros requisitos ${ }^{8}$ - e, se ultrapassar essa fase de maneira positiva, já passa à verificação da própria repercussão geral, inicialmente pelo relator, com a inserção de seu voto no plenário virtual, com início do prazo para que os demais também o façam, no prazo de 20 dias. Evidente que somente se analisará a repercussão geral se a matéria for inédita ou pedido de revisão de tese sobre a repercussão geral antes negada. A legitimidade, então, é do recorrente sobre a demonstração, sem poder o juízo recursal analisar uma repercussão geral oficiosamente, se houver ausência desta no recurso.

No entanto, não será qualquer recurso que servirá de base para o julgamento de um caso em repercussão geral, apesar de todos os recursos terem a menção sobre a repercussão geral, tal desiderato de escolha fica a critério do próprio relator.

Desse modo, o relator do recurso sobre o qual se analisa a repercussão geral insere o seu voto sobre a concessão ou não neste plenário virtual ${ }^{9}$ do STF, nesse momento, abre-se o prazo de 20 dias para cada ministro votar sobre a repercussão geral.

Na hipótese da abstenção de um ministro nos 20 dias, é computado como um voto pela repercussão. Normalmente, se a matéria for de turma, primeiro estes votam, já que para a concessão da repercussão geral, há a necessidade de somente quatro votos, o que já pode-se alcançar internamente dentro da turma. Quando não se consegue a repercussão dentro da votação da turma, os outros ministros alheios àquela turma também proferem o voto.

Para a recusa da repercussão geral são necessários, no mínimo, oito votos. Na repercussão geral, a admissibilidade desta se confunde com a admissibilidade do próprio recurso extraordinário.

7 "Não há mais a necessidade de que a repercussão geral seja inserida em tópico específico diante do novo ordenamento, apesar de haver jurisprudência do STF em sentido contrário. Entretanto, não quer dizer que o recorrente possa interpor o extraordinário sem a devida comprovação, somente não há necessidade de que esteja em um tópico em separado, mera formalidade: "No regime original do CPC/73, era necessário que o recorrente demonstrasse a existência de repercussão geral em preliminar destacada. Agora, ao contrário, o § 2.o apenas exige que fique clara e fundamentada a existência de repercussão, não sendo mais necessário o destaque em tópico/preliminar específico. Isso não quer dizer, no entanto, que esse destaque não possa ser feito.” NUNES, Dierle; BAHIA, Alexandre; PEDRON, Flávio Quinaud. Comentários ao art. 1.030. STRECK, Lenio. Comentários ao código de Processo Civil, 11ª edição.. Saraiva, 3/2016. [Minha Biblioteca]. Retirado de https://integrada.minhabiblioteca.com.br/\#/books /9788502635609/

8 Apesar da repercussão geral ser um requisito de admissibilidade, deve somente ser analisada se presente os outros requisitos: Regimento Interno - STF - Artigo. 323. Quando não for caso de inadmissibilidade do recurso por outra razão, o(a) Relator(a) submeterá, por meio eletrônico, aos demais ministros, cópia de sua manifestação sobre a existência, ou não, de repercussão geral. $\$ 1^{\circ}$ Tal procedimento não terá lugar, quando o recurso versar questão cuja repercussão já houver sido reconhecida pelo Tribunal, ou quando impugnar decisão contrária a súmula ou a jurisprudência dominante, casos em que se presume a existência de repercussão geral. \$2º Mediante decisão irrecorrível, poderá o(a) Relator(a) admitir de ofício ou a requerimento, em prazo que fixar, a manifestação de terceiros, subscrita por procurador habilitado, sobre a questão da repercussão geral.

9 "Há um sistema eletrônico que substitui o julgamento no plenário ou na turma, sem a necessidade de reunião física dos ministros do Tribunal. "Criado em 2007, o Plenário Virtual é um sistema que permite aos ministros do Supremo Tribunal Federal deliberarem se determinada matéria apresenta ou não repercussão geral, pré-requisito introduzido pela Emenda Constitucional 45/2004 para admissão de Recurso Extraordinário. Um dos objetivos da reforma foi o de reduzir a quantidade de causas remetidas à última instância do Judiciário, permitindo ao STF se dedicar a questões mais relevantes.” http://www.conjur.com.br/2014-jul-27/750-temas-passaram-plenario-virtual-stf 
É pertinente entender que apesar de todo recurso extraordinário conter uma defesa de incidência de repercussão geral, para o julgamento de recurso extraordinário sob o rito da repercussão geral, influenciando como uma tese jurídica afetada, não há a influência de qualquer recorrente na escolha de qual será o recurso base para tal análise.

\subsection{Recursos excepcionais repetitivos}

No caso dos recursos repetitivos, não há requerimento do requerente para que o rito seja alterado do julgamento comum para o repetitivo, a legitimidade é oficiosa, ocorrendo de duas maneiras: pelo presidente ou vice-presidente do Tribunal recorrido ou pelo relator no Tribunal Superior.

Desse modo, a atribuição de um rito repetitivo ao recurso excepcional independe de requerimento, estando a cargo somente da análise judicial. O interesse sobre a alteração do rito acaba por ser do próprio Judiciário, dependendo de sua verificação e dentro do seu controle de gestão judicial, sem a interlocução com qualquer das partes, seja para afetar uma matéria como repetitiva, seja para não vislumbrar uma matéria evidentemente repetitiva como necessária de um rito específico para formar um precedente vinculante.

A análise dos critérios da multiplicidade, do impacto processual e da necessidade da transformação daqueles recursos excepcionais em um rito repetitivo continua sem um diálogo processual, somente com a menção do próprio Judiciário, o que acaba por parecer ser um instituto mais de conveniência à atividade jurisdicional do que para a formação adequada de um precedente vinculante.

Dentro das competências e hipóteses delineadas no CPC/2015, dificilmente um presidente ou vicepresidente de um Tribunal recorrido realiza essa análise, interferindo diretamente no trabalho do STJ ou STF, apesar de ser, pelo próprio texto legal, a primeira e maior aposta das formas, com o recurso chegando ao Tribunal Superior já imbuído de uma visão repetitiva, para somente a confirmação pelo relator.

O normal, dentro do cotidiano, da utilização do instituto recai na análise do próprio Tribunal sobre a iniciativa de tal atribuição, com o encargo ao relator. No entanto, no STJ, recentemente, houve a alteração regimental para que o relator somente proponha a análise e que não mais a própria competência para a mudança procedimental, apesar de a lei permitir expressamente. De fato, um acerto do regimento, com uma cautela maior e, ainda, com uma análise minuciosa e sem a corrida dos relatores para ser o protagonista do precedente.

Mesmo sem a previsão legal, creio ser pertinente a possibilidade do recorrente, seja no bojo da peça recursal ou em petição avulsa, requerer que seja analisada a possibilidade do mesmo ser encarado como repetitivo, elencando os motivos de tal desiderato, afinal, o que o juízo pode realizar oficiosamente, as partes podem requerer a fazê-lo.

Todavia, não haveria necessidade de resposta ou análise pelo relator sobre a questão.

\subsection{Incidente de arguição de inconstitucionalidade}

No incidente de arguição de inconstitucionalidade a legitimidade é ampla ${ }^{10}$, com a possibilidade pelas partes, pelo Ministério Público e de maneira oficiosa, no entanto, essa alegação da inconstitucionalidade em determinada lei que fundamenta o objeto recursal deve ser sempre de maneira incidental na demanda.

10 A legitimidade para a arguição de inconstitucionalidade deve ser vista neste prisma: "Logo, se o ato normativo que sustenta determinado direito no bojo de uma causa for inconstitucional, as partes ou o Ministério Público poderão arguila perante o juiz ou o órgão fracionário (Turma ou Câmara, respectiva). Até mesmo o juízo da causa, seja ele singular ou colegiado, poderá, de ofício, pronunciar-se sobre a inconstitucionalidade que esteja a inquinar disposição nor- mativa que tenha reflexo sobre a demanda." FREIRE, Alexandre; SCHMITZ, Leonard Ziesemer; STRECK, Lenio Luiz. Comentários ao art. 948. STRECK, Lenio. Comentários ao código de Processo Civil, 11 edição. Saraiva, 3 /2016. [Minha Biblioteca]. Retirado de https:/ /integrada.minhabiblioteca.com.br /\#/books /9788502635609/ 
Em todos os casos, o momento para o pedido ou a manifestação - no caso do juízo - deve ater-se a ser até o julgamento do recurso ou processo ${ }^{11}$. Se a arguição for pelas partes, pode ser no próprio bojo recursal ou, ainda, em petição avulsa ou durante a sustentação oral. No caso do Ministério Público é apropriado ser no momento do seu parecer ministerial, contudo não há nenhum óbice que seja em apartado ou, ainda, na própria manifestação oral durante a sessão de julgamento. Se for de ofício, o relator insere em seu voto tal proposição, se for por qualquer outro membro do colegiado, será durante os debates de julgamento daquele recurso.

Realizada a arguição de inconstitucionalidade - por qualquer dos legitimados - o órgão fracionário suspenderá o julgamento da demanda ou nem iniciará, passando à análise do incidente, em juízo prévio, com a visualização preliminar sobre a possível inconstitucionalidade, o que podemos enquadrar como um juízo de admissibilidade daquela suscitação. Marinoni e Mitidiero dispõem que não seria uma admissibilidade e, sim, que os membros desse colegiado menor devem proferir o seu voto sobre a inconstitucionalidade, contudo não podem declarar pela reserva de plenário ${ }^{12}$.

De todo modo, há essa análise, a qual definirá sobre a instauração do incidente.

Se o resultado for pela constitucionalidade, o incidente é rejeitado, com o afastamento da questão e o prosseguimento do julgamento daquele recurso ou processo originário. Por outro lado, se resultar pela incidência da inconstitucionalidade ${ }^{13}$, ocorrerá a suspensão daquele julgamento, com a remessa do feito para o pleno ou órgão especial.

Nesse órgão, não há mais necessidade de admissibilidade, uma vez que neste momento, todos os membros deste colegiado competente para a análise sobre a declaração de inconstitucionalidade votará sobre a sua posição sobre esse ponto.

\subsection{Incidente de resolução de demandas repetitivas}

No IRDR, a legitimidade para o pedido de instauração, nos moldes do art. 977, está delineada da seguinte maneira: pelo juiz, pelo relator, pelas partes, pelo Ministério Público e Defensoria Pública.

O IRDR possibilitou uma amplitude da legitimidade, permitindo tanto de ofício, pelo juiz de primeiro grau $^{14}$ ou o relator, ou por requerimento, pelas partes, Ministério Público e Defensoria Pública. No entanto, há uma diferença sobre a forma do pedido quanto aos demais institutos ${ }^{15}$, pelo fato de ser em

11 Não há momento correto para que se possa arguir determinada inconstitucionalidade, somente há o momento limite, que será o próprio julgamento do recurso: "A parte pode arguir a inconstitucionalidade em qualquer peça do processo, inclusive petição avulsa que junte aos autos durante a tramitação perante o órgão fracionário, ou até, se for o caso, em sustentação oral, na sessão de julgamento. Não há preclusão em se tratando de quaestio iuris” MOREIRA, José Carlos Barbosa. O novo processo civil brasileiro: exposição sistemática do procedimento. 27. ed, Ed. Forense, 2008. p. 183.

12 Conceituando a regra do Full Bench ou cláusula de reserva de plenário: "Trata-se de regra que estabelece um quorum qualificado para o reconhecimento da inconstitucionalidade no âmbito dos tribunais - regra da reserva de plenário ou regra do 'full bench'. Estabelece-se uma regra de competência funcional (cujo desrespeito implica incompetência absoluta) para o reconhecimento da inconstitucionalidade de lei.” CUNHA, Leonardo José Carneiro da; DIDIER JR., Fredie. Curso de direito processual civil. Meios de impugnação às decisões judiciais e processo nos tribunais. 13ª ed. Salvador: JusPodivm, 2016. p. 671.

13 Neste mesmo sentido: "Se acolher o incidente, o órgão fracionário lavrará o acórdão, onde reconhecerá, mesmo que em juízo prévio, a inconstitucionalidade da lei ou do ato do Poder Público, a fim de que a questão relacionada seja submetida ao Plenário ou ao Órgão Especial, onde houver." MADRUGA, Eduardo; MOUZALAS, Rinaldo; TERCEIRO NETO, João Otávio. Processo Civil Volume Único. 8a. ed. revisada, ampliada e atualizada. Salvador, Ed. JusPodivm, 2016. p. 945

14 O juiz é figura importante para a suscitação do IRDR, podendo este identificar que há uma multiplicidade. Entretanto, há necessidade de uma causa existente no tribunal? Não vejo essa necessidade, mas a maioria da doutrina, sim. "A referência ao juiz sinaliza o caso em que o IRDR se inicia em primeiro grau - conquanto seja dirigido ao tribunal." MANCUSO, Rodolfo de Camargo. Incidente de resolução de demandas repetitivas: a luta contra a dispersão jurisprudencial excessiva.1a. ed. São Paulo: Ed. RT. 2016. p. 219.

15 Ponto relevante levantado por Nery Jr. e Nery passa pela necessidade de que os legitimados comprovem a existência dos requisitos pertinentes ao próprio IRDR, mas, sobretudo, deve comprovar a vinculação com a causa: "São o relator ou o 
um procedimento autônomo, com a distribuição como se fosse uma inicial, ensejando a necessidade de instrução com documentos necessários à demonstração do preenchimento dos pressupostos para a instauração do incidente, bem como daqueles para a melhor exposição fática para a delimitação do que seria ratio decidendi, possibilitando uma melhor verificação pelo órgão julgador do cumprimento dos requisitos.

O pedido tem endereçamento ao presidente do Tribunal de segundo grau, que remete ao órgão ${ }^{16}$ responsável pela pacificação da jurisprudência naquele Tribunal, ou seja, o órgão anterior - câmara ou turma - não influenciará na admissibilidade, tampouco realiza alguma ingerência sobre o instituto.

Por essa visão, o IRDR nasce já autônomo ${ }^{17} \mathrm{em}$ relação ao processo que enseja a sua própria existência, transcorrendo de maneira apartada, com uma petição ou ofício inaugurando o procedimento próprio, apesar de basear-se em um processo existente, não está interligado a este, sendo realmente um incidente autônomo.

No entanto, é possível que o relator, caso entenda pertinente, paute no seu órgão originário a possibilidade de suscitar o IRDR, ou seja, a transformação da decisão de realizar o ato oficioso de maneira unipessoal pelo relator, para uma decisão colegiada, visualizando que possam decidir se mandarão ofício ou não, ainda que, posteriormente, este ficará a cargo do relator para o pedido e sua distribuição.

Uma vez distribuído o IRDR para este órgão, com o sorteio de um relator dentre os membros deste colegiado, o pedido de instauração deve ser colocado em pauta para o julgamento da admissibilidade - sempre de maneira colegiada, baseando na presença ou não dos requisitos do art. 976, I e II. Sem a verificação da presença dos requisitos do instituto - multiplicidade, risco à segurança jurídica e isonomia, questão de direito - deve haver a rejeição, sem a possibilidade recursal de tal ato. Por outro lado, com o cumprimento destes requisitos, o incidente é instaurado, permitindo ao relator proferir, posteriormente, a decisão de afetação.

O pedido independe do pagamento de custas processuais e o momento para tal feito - via pedido ou ofício - deve ser antes do julgamento do recurso ou da sentença se for por juiz de primeiro grau ${ }^{18}$,

órgão colegiado para o qual o processo foi distribuído, mediante ofício, bem como as partes, o MP e a Defensoria Pública, mediante petição fundamentada. Em qualquer caso, o ofício ou a petição não podem deixar de conter a documentação que demonstre ser necessário e útil o incidente.” NERY JR, Nelson; NERY, Rosa Maria de Andrade. Código de Processo Civil Comentado. 16a. Ed. São Paulo. RT. 2016. p. 2.115.

16 A nova codificação processual não determinou os órgãos internos dos tribunais, justamente pela composição de cada instituição, uma vez que são díspares em suas quantidades de membros: "A legislação infraconstitucional pode indicar o tribunal competente, seguindo as regras já traçadas pela Constituição Federal. O legislador deve apontar qual o tribunal competente, não estabelecendo qual o órgão interno do tribunal que deva realizar determinado julgamento. Se o órgão julgador, num determinado tribunal, é uma câmara cível, um grupo de câmaras, a corte especial ou o plenário, isso há de ser definido pelo seu respectivo regimento interno. O que importa é que o tribunal seja aquele previsto na Constituição Federal.” CUNHA, Leonardo José Carneiro da. Anotações sobre o incidente de resolução de demandas repetitivas previsto no projeto do novo Código de Processo Civil. Revista de Processo. São Paulo: Editora RT, março 2011. p. 271 /272.

17 O IRDR não é um incidente que acompanha o processo, mas, autônomo, com protocolo e distribuição apartada daquele originário, inclusive com novo relator para o feito. Há, ainda, quem entenda que nem precisa ser vinculado a um processo, podendo ser uma conjunção de vários processos: "De outra parte, o endereçamento do IRDR ao "presidente do tribunal” deve ser entendido no sentido de caber a essa autoridade recepcionar o procedimento e, ato contínuo, distribuí-lo ao órgão a quem cabe proceder o juízo de admissibilidade.” MANCUSO, Rodolfo de Camargo. Incidente de resolução de demandas repetitivas: a luta contra a dispersão jurisprudencial excessiva.1a. ed. São Paulo: Ed. RT. 2016. p. 217.

18 O juiz de primeiro grau pode suscitar o IRDR, por ter legitimidade para tanto. Uma dúvida surge, então: um juiz de juizado pode propor o IRDR? A meu ver, sim. Não pode ter um IRDR no âmbito dos juizados, mas eles são subordinados ao que se decidiu no incidente, o que leva aos juízes de sua competência poderem propor, ainda que não possam julgar. Em sentido contrário, inadmitindo a aplicabilidade de vinculação ao juizado, Scheleder pontua: "É por esse, e por todos os demais argumentos apresentados, que o novo incidente, em relação aos juizados especiais, revela-se inconstitucional e incompatível. No entanto, longe de desmerecer a finalidade e o progresso do direito conquistado com o novo Código de Processo Civil, tecido com o ânimo de um processo democrático. Ao contrário. O que se quer demonstrar é apenas a inconstitucionalidade da previsão de vinculatividade da tese construída a partir do incidente de resolução de demandas repetitivas, como previsto no CPC/2015, ao sistema dos juizados e, portanto, a aplicação deste instrumento aos juizados especiais deve ser cautelosa e remediada.” SCHELEDER, Adriana Fasolo Pilati. A inconstitucionalidade da aplicação do 
pelo seu fator incidental. Pode ser a qualquer momento em primeiro grau e, em segundo grau, tem a limitação do julgamento do recurso, que torna desnecessária a instauração do incidente.

\subsection{Incidente de assunção de competência}

No IAC ${ }^{19}$, o instituto deve ser suscitado pelos seus legitimados - do juízo, da parte, do Ministério Público ou da Defensoria Pública, até o julgamento do recurso, remessa necessária ou competência originária, perante a turma ou colegiado competente para este julgamento. O pedido pode ser na própria peça recursal ou inicial, em petição avulsa ou na sustentação oral pelas partes, no caso do Ministério Público na sua manifestação oral durante a sessão.

Com o requerimento do IAC, há a suspensão do julgamento principal, para realizar-se a análise da admissibilidade, pelo próprio colegiado menor $^{20}$. Nessa análise preliminar, há a verificação do preenchimento dos requisitos impostos pelo art. 947, com duas possibilidades decisórias incidentais: rejeitar o incidente, ultrapassando a questão, voltando ao julgamento do recurso em si ou admitir o incidente, não julgar o recurso e remeter ao colegiado competente para o julgamento da assunção de competência.

No caso da análise preliminar positiva ${ }^{21}$, o processo, com o recurso/remessa/competência originária e o incidente, deve ser remetido ao órgão competente - mais amplo - para o julgamento, tanto da parte principal do processo, bem como do incidente, o qual deve analisar, de maneira definitiva, o juízo de admissibilidade da instauração do incidente, com a verificação dos requisitos diante dos argumentos apresentados, seja de ofício ou por requerimento dos legitimados.

O resultado desta análise pode ser a rejeição da instauração do incidente ou a admissibilidade positiva, com a instauração do incidente. No caso de inadmissibilidade, há a devolução para o colegiado originário, para que este julgue o pedido principal, sem mencionar o incidente, já que restou inadmitido.

\section{A escolha do recurso ou processo representativo da controvérsia}

O processo ou recurso base de qualquer dos institutos insertos ao microssistema de formação de precedentes vinculantes deve conter algumas especificações para que esteja nesse posto, dada a importância inerente ao impacto que qualquer julgamento por amostragem fará aos demais processos existentes ou àqueles futuros que tratarão sobre a mesma matéria.

incidente de resolução de demandas repetitivas nos juizados especiais. Florianópolis, SC, 2015.410 p. Tese (doutorado). Universidade Federal de Santa Catarina, Centro de Ciências Jurídicas. Programa de Pós-Graduação em Direito. p. 371.

19 Mais detalhado sobre o tema: LEMOS, Vinicius Silva. Incidente de assunção de competência. Da conceituação à procedimentalidade. 1a. Ed. Jus Podivm. Salvador. 2018.

20 A admissibilidade deve ser realizada pelo órgão menor e, posteriormente, pelo órgão maior. No entanto, Theodoro Jr. entende que seria somente pelo relator do primeiro órgão, o qual já remeteria ou negaria a matéria, discordamos dessa visão: "O incidente se desdobra em duas fases, cabendo ao relator, na primeira, deliberar, de ofício ou a requerimento, sobre o cabimento e a conveniência da submissão da causa ao julgamento do órgão regimentalmente encarregado da uniformização da jurisprudência do tribunal (art. 947, § 1º)." THEODORO JR., Humberto. Regime das demandas repetitivas no novo código de processo civil. Coleção Novo CPC - Doutrina Selecionada - v.6 - Processo nos Tribunais e Meios de Impugnação às Decisões Judiciais. Organizadores: DIDIER JR., Fredie; FREIRE, Alexandre; MACEDO, Lucas Buril de; PEIXOTO, Ravi. 2a. Ed. JusPodivm, Salvador, 2016. p. 443.

21 E, apesar da omissão do ordenamento sobre o procedimento do IAC, a sua admissibilidade é realizada de maneira bifásica, pelo órgão competente originariamente para o recurso e, posteriormente, pelo órgão para onde se remeteu o IAC: "Vale ressaltar, que essa decisão é tomada em duas instâncias sucessivamente: em primeiro lugar, pelo órgão que seria naturalmente competente para julgar o recurso e em seguida pelo órgão designado pelo regimento interno como responsável pelo exame do julgamento por assunção de competência. Apenas quando for obtida decisão positiva em ambos os órgãos é que o deslocamento poderá ocorrer, outorgando-se ao novo colegiado competência para julgar o recurso." MARINONI, Luiz Guilherme; ARENHART, Sérgio cruz; MITIDIERO, Daniel. Novo Curso de Processo Civil: Tutela dos Direitos Mediante Procedimento Comum. São Paulo: Revista dos Tribunais, v.2. 2015. p. 56. 
Dessa maneira, pertinente que o recurso - ou os recursos - representativo da controvérsia seja capaz de trazer em seu arcabouço jurídico, uma densidade material e argumentativa acima da média, uma vez que, ao ser escolhido para representar a controvérsia, representará todo a controvérsia ali instaurada, como salienta Marinoni, em casos pendentes no próprio Tribunal ${ }^{22}$.

Essa escolha ${ }^{23}$ não é bem delineada pelo ordenamento ${ }^{24}$, ainda mais nos institutos em que a legitimidade seja do próprio Judiciário, sem qualquer fixação de critérios específicos e objetos para tal procedimento. Por isso, totalmente pertinente que se estude e proponha essa fixação de critérios mínimos ${ }^{25}$ para que haja uma clareza maior nas escolhas dos representativos da controvérsia.

Como vimos nos meios de suscitação, teremos institutos em que o próprio Judiciário que escolhe, bem como outros as partes podem suscitar, o que tornam, de certa maneira, o seu processo ou recurso como representativo da controvérsia, ao menos inicialmente.

\subsection{A escolha realizada de ofício pelo relator ou colegiado e a necessidade de critérios}

Em todos os institutos do microssistema é possível a suscitação oficiosa de que determinado processo está apto a ser julgado de modo diverso do comum, criando um rito específico, dentre os possíveis para aquela situação, para o julgamento, alterando a tramitação normal daquela demanda.

Com essa oficiosidade permitida, o Judiciário fica com o poder de determinar que uma matéria será julgada de modo ao seu resultado vincular para outras demandas existentes ou futuras, o que é totalmente pertinente, mas que necessita de transparência de critérios para tal alteração.

Tem institutos em que somente o Judiciário poderá fazer tal escolha, sem a interferência de nenhum outro ator processual, na repercussão geral e nos recursos excepcionais repetitivos. Não há, em nenhum desses institutos, uma suscitação pela parte - ou outro legitimado - de que determinado processo seja o representativo da controvérsia.

Naqueles em que outros legitimados podem suscitar, qual assim procedem, há a naturalidade do processo suscitante ser a base inicial para a representação da controvérsia, contudo em qualquer instituto do microssistema quando a suscitação é oficiosa, não há critério algum para a escolha dos representativos da controvérsia.

22 Marinoni prevê que o tribunal que for realizar a seleção dos representativos da controvérsia, seja no Recurso Especial, sobre o qual escreve, mas todos os outros que irão escolher, para afetar ou depois da afetação, como no IRDR, devem preocupar-se não somente com a controvérsia, mas como o impacto nos casos pendentes, afinal, a amostragem pertinente à formação do precedente é importante para visualizarmos de que o julgamento como um todo é diferente do rito norma do julgamento de um recurso. "Contudo, em caso de recurso repetitivo, em que se elabora precedente considerando-se casos pendentes, a necessidade de a Corte buscar a essência da discussão a partir da seleção de casos realmente representativos da controvérsia pode ter outra conotação. Aqui não importaria apenas a circunstância de que a Corte não está decidindo para as partes, porém o fato de que a Corte está a decidir um caso pendente em vários recursos” MARINONI, Luiz Guilherme. O "problema" do incidente de resolução de demandas repetitivas e dos recursos extraordinário e especial repetitivos. Revista de Processo. vol. 249. ano 40. p. 399-419. São Paulo: Ed. RT, nov. 2015. p. 415.

23 Câmara já demonstra a preocupação e a importância dessa escolha: "Questão importante é a de saber que recursos devem ser selecionados para aplicação dessa técnica especial de julgamento por amostragem.” CÂMARA, Freitas, A. (01/2017). O Novo Processo Civil Brasileiro, $3^{\underline{a}}$ edição. [Minha Biblioteca]. Retirado de https://integrada.minhabiblioteca. com.br/\#/books/9788597009941/

24 Não só a escolha dos representativos da controvérsia não é delineada em termos criteriosos no ordenamento, bem como não há na doutrina tanto arcabouço de estudo sobre o tema, com a necessidade de fixação de melhores critérios e menos discricionariedade. Sobre o tema, há um grande artigo específico e alguns estudos gerais sobre precedentes. O artigo: CABRAL, Antônio do Passo. A escolha das causa-piloto no incidente de resolução de demandas repetitivas. Revista de Processo. v. 231, Maio/2014.

25 "A lei processual estabelece expressamente a exigência de que sejam selecionados "recursos admissíveis que contenham abrangente argumentação e discussão a respeito da questão a ser decidida” (art. 1.036, § 6o). Vê-se, assim, que só recursos admissíveis podem ser selecionados, o que é essencial para que se possa promover o exame do mérito, sob pena de frustrarem-se os objetivos a alcançar com o emprego desta especial técnica processual.” CÂMARA, Freitas, A. (01/2017). O Novo Processo Civil Brasileiro, $3^{\underline{a}}$ edição. [Minha Biblioteca]. Retirado de https://integrada.minhabiblioteca.com.br/\# / books /9788597009941/ 
Dada essa ausência de critérios, é importante a fixação de pontos pertinentes para que o relator ou o colegiado possam legitimar tal processo para representar a controvérsia. Se for um instituto que somente um processo é julgado, que seja escolhido um que contenha a melhor delimitação fática, uma argumentação jurídica das partes com um arcabouço suficiente para delinear a afetação, a existência de contraditório na demanda e o julgamento e a preferência por processo coletivo ${ }^{26}$ sobre a matéria.

Se o instituto permitir um julgamento de mais demandas como representativos da controvérsia que amplie-se para processos que detenham resultados decisórios diversos e com recursos - se for o caso - com pleitos diversos. Ou seja, mesmo diante da mesma matéria, um processo que a sentença foi procedente e a apelação seria pela improcedência e outro processo de modo inverso, sentença improcedente e a apelação pela procedência.

Essa pluralidade de finalidades das partes nos processos possíveis como representativos da controvérsia ajudam a permear uma diversidade argumentativa própria dos recursos serem em caminhos e requerimentos distintos.

Toda essa visão de fixação de critérios $^{27}$ é pertinente para que o relator ou o colegiado como um todo possa fundamentar para a sociedade, de modo endo e extraprocessual, os motivos que aquele determinado processo - ou processos - foi escolhido como representativo da controvérsia, concedendo um processo mais democrático à própria formação do precedente vinculante.

Se o julgamento é por uma amostra mínima para a aplicabilidade em um todo, pertinente que, nessa escolha dos recursos, haja uma contemplação de todos os fundamentos possíveis ${ }^{28}$ ou a maior amplitude sobre a matéria. Cada recurso, mesmo diante de somente um assunto, argumenta de forma diversa, com teorias diversas sobre aqueles fatos ou matéria, com uma gama de fundamentos diferentes almejando, por vezes, o mesmo resultado.

\subsubsection{Repercussão geral}

Na repercussão geral, todos os recursos extraordinários devem suscitar tal requisito de admissibilidade, demonstrando a referida transcendência, o que possibilita uma discricionariedade do juízo, no caso os

26 Em outra visão, Didier Jr. e Zaneti Jr. entendem que se houver um processo coletivo a ser julgado, este seria impeditivo para o julgamento repetitivo, no caso utilizam o IRDR como comparativo. Pensamos diferente, pela inclusão das duas técnicas quando couber, sendo o coletivo o representativo da controvérsia: "É possível, inclusive, criar uma diretriz para o incidente de resolução de demandas repetitivas em Tribunal de Justiça ou Tribunal Regional Federal: a existência de ação coletiva, pendente no Estado ou na Região, enquanto não estiver no Tribunal, seria fato impeditivo da instauração do incidente; a pendência da ação coletiva deveria levar à suspensão, até mesmo de ofício, dos processos individuais, tal como defendido em outro lugar e sufragado pelo STJ." DIDIER JR., Fredie; ZANETI JR., Hermes. Ações coletivas e o incidente de julgamento de casos repetitivos - espécies de processo coletivo no Direito brasileiro: aproximações e distinções. Revista de Processo | vol. $256 / 2016$ | p. 209 - 218 | Jun / 2016. p. 216.

27 Existem delimitações mínimas que o recurso representativo da controvérsia deve conter nos recursos repetitivos, mas não vislumbro como requisitos determinantes para essa escolha, continuando a existência de discricionariedade para tanto. "Importante observação ainda se faz em relação ao $\$ 6^{\circ}$, que indica os requisitos para a escolha dos recursos representativos da controvérsia: i) recursos admissíveis, ou seja, aqueles cujos requisitos de admissibilidade estão devidamente preenchidos; ii) abrangente argumentação; e iii) abrangente discussão.” PITTA, Fernanda. Comentário ao art. 1.036. Novo Código de Processo Civil Comentado - Tomo III (art. 771 ao art. 1.072). Orgs: RIBEIRO, Sergio Luiz Almeida; GOUVEIA FILHO, Roberto Pinheiro Campos; PANTALEÃO, Izabel Cristina; GOUVEIA, Lucio Grassi de. Ed. Lualri, São Paulo, 2017. p. 406.

28 Concordamos que a busca pelo representativo da controvérsia seja a busca pelo processo ou recurso ideal, contudo este estudo tem o intuito de tentar entender os critérios existentes e objetivá-los, retirando do ideário do juízo tal premissa ou condão. "Com relação à abrangente argumentação e discussão, percebe-se que o Código pretenda que seja selecionado como representativo da controvérsia aquele cuja argumentação tenha extensão e também profundidade, ou seja, quantitativamente e qualitativamente. Seria o "recurso ideal" aquele com maior número de argumentação (na tentativa de esgotar as fundamentações relacionadas à matérias) e que essas argumentações estejam bem desenvolvidas.” PITTA, Fernanda. Comentário ao art. 1.036. Novo Código de Processo Civil Comentado - Tomo III (art. 771 ao art. 1.072). Orgs: RIBEIRO, Sergio Luiz Almeida; GOUVEIA FILHO, Roberto Pinheiro Campos; PANTALEÃO, Izabel Cristina; GOUVEIA, Lucio Grassi de. Ed. Lualri, São Paulo, 2017. p. 406. 
ministros, para que o recurso que se será colocado na pauta para a verificação da repercussão geral seja o melhor possível diante da complexidade da controvérsia, o mais completo materialmente possível.

Na visão de Marinoni e Mitidiero, esse momento é de suma importância, com a necessidade de reflexão profunda entre os ministros, como dito antes, e, assim, ser a "mais dialogada possível a fim de que se selecione um ou mais recursos que representem adequadamente a controvérsia ${ }^{29 "}$.

Entretanto, se o relator que realizar a análise da repercussão geral, anteriormente aos demais, escolher um recurso que não represente bem a controvérsia ali suscitada, não há como, nos dizeres de Talamini, a parte suscitar que seja escolhido o seu recurso extraordinário para servir de amostra à repercussão geral $^{30}$, contudo, outros ministros podem sugerir a junção do julgamento com recursos que igualmente representem a controvérsia, com argumentos novéis e diversificados.

\subsubsection{Recursos excepcionais repetitivos}

Nos recursos excepcionais repetitivos, a questão é mais complexa ${ }^{31}$, uma vez que iniciativa é totalmente oficiosa, com a escolha partindo do relator - ou o presidente/vice-presidente do Tribunal recorrido para que haja a afetação da matéria, com a devida escolha aleatória e subjetiva daqueles dois ou mais recursos que serão os representativos da controvérsia.

O intuito da representação da controvérsia é ampliar os fundamentos recursais, para esgotar todas as possibilidades jurídicas da questão repetitiva, de modo a possibilitar ao tribunal superior, um exaurimento da matéria colocada em questão, para facilitar a adequação posterior desta decisão, para a maior quantidade dos recursos idênticos que estão à espera da definição do julgamento que culminará em um precedente vinculante.

Contudo, apesar de se ter a noção do que deve ser feito, qual o resultado que se espera, não há uma regra para a escolha desses recursos que serão transformados em repetitivos, somente a regulamentação, pelo art. 1.036, $\S \S 1^{\circ}$ e $5^{o}$, da possibilidade do presidente/vice-presidente ou depois o relator selecionar, diante da multiplicidade, dois ou mais recursos para representarem a controvérsia, sem nenhuma delimitação objetiva de critérios para tal desiderato. Lamy e Sofia Temer, acertadamente, criticam essa subjetividade, evidenciando "a ausência de elementos objetivos para possibilitar a escolha do recurso que irá representar todos os demais (...) nenhum dos instrumentos processuais prevê mecanismos idôneos a garantir a adequada atuação do representante e, por via de consequência, a própria participação dos interessados no processo ${ }^{32 "}$ ".

É um equívoco essa total discricionariedade dos ministros nos recursos excepcionais repetitivos - ou dos presidentes/vice-presidentes - para a escolha do recurso representativo da controvérsia, ainda

29 MARINONI, Luiz Guilherme; MITIDIERO, Daniel. Repercussão geral no recurso extraordinário. 2. Ed. São Paulo: Editora RT, 2008. p. 70.

30 A atribuição, como vimos, da análise da repercussão geral nasce pela iniciativa do relator, ao colocá-lo em plenário virtual, não abrindo possibilidade da parte escolher se o seu recurso será o representativo, uma vez que todos os recursos devem constar a alegação da citada repercussão: "Contudo, a parte não tem o direito de exigir que o seu recurso sirva como amostra, sob o argumento de que ele está melhor formulado ou fundamentado” TALAMINI, Eduardo. Novos Aspectos da Jurisdição Constitucional Brasileira: Repercussão Geral, Força Vinculante, Modulação dos Efeitos do Controle de Constitucionalidade e Alargamento do Objeto do Controle Direto, São Paulo, Tese de Livre-Docência, USP, 2008. p. 69.

31 Se há uma multiplicidade, o responsável pela escolha deve entender que o melhor processo ou os melhores, devem ser escolhidos como representativos da controvérsia. Cabral dispôs sobre isso ainda na antiga codificação, porém, o novel ordenamento não primou por estabelecer critérios: "Pois bem, quaisquer destes juízos, diante de uma multiplicidade de casos, devem selecionar um deles para provocar a instauração do incidente. Ora, portanto, também quando se trata de órgãos judiciários, algumas situações podem refletir hipóteses em que existe uma verdadeira "seleção", estratégica ou não, do processo que será a base para o procedimento dos incidentes. Em suma, para muitos sujeitos envolvidos, pode-se identificar uma verdadeira "escolha”." CABRAL, Antônio do Passo. A escolha das causa-piloto no incidente de resolução de demandas repetitivas. Revista de Processo. v. 231, Maio/2014. p. 206.

32 LAMY, Eduardo de Avelar; TEMER, Sofia Orberg. A representatividade adequada na tutela de direitos individuais homogêneos. GRINOVER, Ada Pellegrini et al. (Coord.) Processo coletivo: do surgimento à atualidade. São Paulo: Revista dos Tribunais, 2014. p. 921-922. 
mais pelo fato de que a afetação é o início do próprio procedimento, com a importância tamanha para a abertura do contraditório ampliado, a manifestação de toda a sociedade para a discussão daquela matéria.

Quanto mais transparente os critérios de escolha do recurso representativo da controvérsia, de igual forma, o procedimento como um todo estará transparente. Não há de ficar, da maneira como funciona, a total critério do ministro, sem maiores coerências. Uma crítica pertinente se faz necessária pela ausência de critérios ${ }^{33}$.

\subsection{O meio mais democrático de escolha por outros legitimados}

Nos outros institutos que delineamos, fora a repercussão geral e os recursos excepcionais repetitivos já esclarecidos, a suscitação pode ser por um outro legitimado que não seja o próprio juízo, oficiosamente e, mediante tal aspecto, há um fator diverso do que os ulteriores, já que enseja um ar mais democrático na própria escolha do representativo da controvérsia.

No IRDR, IAC e incidente de arguição de inconstitucionalidade, tirando o fato de que o juízo possa realizar a escolha de ofício, as partes - ou o Ministério Público e a Defensoria Pública ${ }^{34}$ - podem suscitar o incidente naquela demanda, o que ensejaria uma necessária resposta ao requerimento. Desse modo, não há uma escolha pelo Judiciário do representativo da controvérsia, justamente pela possibilidade dessa matéria de suscitação estar presente em pleito de legitimado e com a necessidade de enfrentamento pelo órgão julgador, com a obrigatoriedade de concessão de resposta ao requerimento formulado, ainda que esse processo suscitante não seja da melhor qualidade processual material sobre a controvérsia.

Não há, portanto, uma escolha pelo juízo sobre o processo representativo da controvérsia quando os outros legitimados suscitam a instauração dos incidentes, justamente pelos legitimados suscitarem em determinados processos e estes servirem, então, como base para a análise da admissibilidade dos incidentes. A concretude necessária para a instauração, ou nã, de cada incidente será a partir daquele que teve a iniciativa de servir de base para ser representativo da controvérsia.

Nessas hipóteses há um aspecto mais dialógico e democrático sobre a instauração, possibilitando as partes e outros legitimados a poderem influenciar na transformação de uma matéria específica em um precedente vinculante. Não ficará somente à escolha do Judiciário, como uma maneira simples

33 "é de grande relevo o exame de qual causa-piloto deve ser aquela escolhida ou admitida e afetada para o julgamento como processo repetitivo." CABRAL, Antônio do Passo. A escolha das causa-piloto no incidente de resolução de demandas repetitivas. Revista de Processo. v. 231, Maio/2014. p. 207.

34 Bueno coloca que o Ministério Público e a Defensoria Pública teriam função diversa como legitimados para suscitar o IRDR e podemos pensar de mesmo modo no IAC. Quando o legislador insere essa legitimidade para o Ministério Público e a Defensoria Público, o faz não nos processos em que esses atuam, justamente por serem representantes ali das partes - ou parte como o Ministério Público em determinadas demandas - e, assim, o legitimado seria a parte, representado por estes entes. Não é o que a lei dispõe. A legitimidade dos entes aqui descrita é para suscitar em processos que não atuem, com ampla legitimidade para tanto, atuando como um terceiro que antevê naquela situação a necessidade da suscitação de um incidente. "Sobre a legitimidade do Ministério Público e da Defensoria Pública, cabe frisar, fazendo eco ao que dispõe o art. 977, III, a propósito do incidente de resolução de demandas repetitivas, que a regra merece ser interpretada amplamente para admitir que a legitimidade daqueles órgãos dê-se tanto quando atuam como parte (em processos coletivos, portanto) como também quando o Ministério Público atuar na qualidade de fiscal da ordem judicial e a Defensoria estiver na representação de hipossuficiente ou, de forma mais ampla, desempenhando seu papel institucional em processos individuais, como amicus curiae." BUENO, Cassio Scarpinella. Novo Código de Processo Civil anotado. 2a. Ed. São Paulo: Saraiva, 2016. p. 594. Se for por um litigante habitual, Ministério Público ou pela Defensoria Pública, o pedido de instauração pode ser de diversos processos ao mesmo tempo, sem guardar identidade com somente um. No caso do Ministério Público, por ser fiscal da ordem jurídica, nem precisaria de ter atuação em um caso, mas, na Defensoria, sim, contudo, pode escolher vários processos para tanto, já indicando uma melhor visão da controvérsia. Outra ampliação que visualizo são para aquelas partes que são litigantes habituais, como telefonias, bancos, dentre outros, que podem suscitar com vários casos ao mesmo tempo : “O tão só fato de ter apartado estes das "partes" indica que o Ministério Público e a Defensoria Pública poderão fazê-lo a partir de processos que não estejam atuando naquela condição.” TEMER, Sofia Orberg. Incidente de resolução de demandas repetitivas. 1a. Ed. Jus Podivm, 2016. p. 190. 
de controle de estoque e sua conveniência, mas possibilita que os demais legitimados influenciem na iniciativa de formar um precedente vinculante.

Desse modo, no IRDR, IAC e na arguição de inconstitucionalidade, a formação do precedente vinculante vindouro resta mais democrático, diante de um procedimento que pode ter como ator processual inicial outro que não seja o próprio Judiciário, não sendo um precedente para atender aos critérios finalísticos eventuais de gestão judicial, mas realmente conceder voz processual à percepção dos demais legitimados a intenção de transformar determinada matéria em precedente vinculante.

Evidentemente que a escolha do processo representativo da controvérsia não será nos mesmos moldes do incidente de repercussão geral ou dos recursos excepcionais repetitivos, uma vez que os legitimados suscitarão em um determinado processo específico, concedendo àquela demanda o condão de ser a base da própria controvérsia.

\subsection{A ampliação dos processos representativos da controvérsia}

Uma vez escolhido o recurso ou processo que provocará o procedimento, caberia a ampliação para mais processos que representem melhor a controvérsia? Ou, ainda, o representativo da controvérsia deve ser estático e ficar somente naquele já escolhido? A primeira resposta geral é no sentido de possibilidade de ampliação, principalmente nos recursos excepcionais repetitivos, cuja prática ${ }^{35}$ já ocorre com a ampliação dos representativos da controvérsia para demais demandas, escolhidas posteriormente.

Primeiro tratando daqueles institutos em que somente ocorre oficiosamente: recursos excepcionais repetitivos e a repercussão geral.

No tocante aos recursos excepcionais repetitivos, ao selecionar aqueles que serão base para o julgamento repetitivo, é necessário a contemplação de todas as teses jurídicas possíveis e visualizáveis daquela questão de direito, como já vimos. Se, para conseguir contemplar a complexidade da matéria, for necessário 5 ou 10 recursos selecionados ${ }^{36}$, não há nenhum problema que a afetação seja nessa quantidade de recursos, quanto maior a diversidade de argumentos possíveis, maior alcance da própria decisão, enfrentando, de maneira pormenorizada, a questão jurídica que ensejou a atribuição do rito repetitivo. Até é aconselhável que tenham recursos com pleitos diversos, um com o pedido de provimento e outro com o pleito pelo improvimento, ambos sobre a matéria a ser afetada.

Para que se alcance a amplitude da discussão material que se almeja, o relator ou colegiado, no Tribunal Superior, pode, independentemente de outros recursos selecionados escolher mais recursos para representar melhor a controvérsia ${ }^{37}$. Essa maior amplitude da controvérsia é salutar para o esgotamento material e das teses, para uma melhor decisão jurídica, ainda mais diante da alteração regimental do STJ sobre a própria decisão de afetação.

35 Esse é um exemplo atual sobre a ampliação da escolha dos representativos da controvérsia feita no STJ: "Novo recurso sobre dano moral por falhas na prestação de serviços de telefonia fixa é afetado como repetitivo. A ministra do Superior Tribunal de Justiça (STJ) Assusete Magalhães determinou, mediante autorização prévia da Primeira Seção, a afetação do REsp 1.525.131 para julgamento sob o rito dos recursos repetitivos. Cadastrado sob o tema 954 em conjunto com o REsp 1.525.174 - afetado em dezembro de 2016 -, o recurso possibilitará a definição de tese sobre a existência de dano moral no caso da cobrança de valores referentes à alteração de planos de franquia ou de serviços nos contratos de telefonia fixa, quando as alterações não tenham sido solicitadas ou autorizadas pelo usuário. Definida a existência do dano, a seção também analisará se deve ser adotado o reconhecimento presumido (in re ipsa) ou se é necessária a comprovação do prejuízo no processo.” Matéria no link: http://www.stj.jus.br/sites/STJ/default/pt_BR/Comunicação/noticias/ Notícias / Novo-recurso-sobre-dano-moral-por-falhas-na-prestação-de-serviços-de-telefonia-fixa-é-afetado-como-repetitivo

36 "Embora formalmente a ampliação da amostragem dos recursos selecionados represente inovação, os tribunais de origem, em regra, selecionam mais de dois recursos como representativos da controvérsia." FREIRE, Alexandre. Comentário ao art. 1.036. CABRAL, Passo, A. D., CRAMER, (orgs.), R. (06/2016). Comentários ao Novo Código de Processo Civil, 2 ${ }^{a}$ edição. [Minha Biblioteca]. Retirado de https://integrada.minhabiblioteca.com.br/\#/books/9788530971441/

37 Nesse sentido: CABRAL, Antônio do Passo. A escolha das causa-piloto no incidente de resolução de demandas repetitivas. Revista de Processo. v. 231, Maio/2014. p. 206. DIDIER Jr. Fredie; TEMER, Sofia Orberg. A decisão de organização do incidente de resolução de demandas repetitivas: importância, conteúdo e o papel do regimento interno do tribunal. Revista de Processo | vol. 258/2016 | p. 257 - 278 | Ago / 2016. p. 266. 
Sobre a repercussão geral, não há a necessidade de que sejam múltiplos processos como representativos da controvérsia, como nos repetitivos, podendo, para tanto, ser somente em um recurso. No entanto, não há nenhum óbice que haja julgamento conjunto daquela matéria com outros recursos que contenham a mesma matéria, com uma amplitude material e argumentativa que contemple uma melhor discussão sobre a matéria a ser julgada em regime de repercussão geral.

No IRDR, não há disposição legal que permita que haja uma suscitação de novos recursos ou processos pra incluir-se como representativos da controvérsia, utilizando como base aquele suscitante para o representativo da controvérsia, o que levaria a não diminuir a influência oficiosa sobre tal escolha.

O fato dessa lacuna é a própria definição do instituto como um julgamento incidental, com a instauração alheia ao processo, com o protocolo e distribuição própria. Dessa maneira, há um procedimento próprio do IRDR, com um trâmite todo delineado pelo art. 976 e seguintes. Apesar de incidental, com um rito procedimental próprio, o IRDR é baseado em um processo existente, não com a definição daquele processo em si, mas com a fixação de uma tese jurídica para ser aplicado, ao mesmo tempo, naquela demanda que propiciou o requerimento do incidente, bem como em outras que, porventura, serão impactadas. Não há, por aquele colegiado, naquele momento, o julgamento da demanda, até pelo fato de poder ser suscitado em processos que estão no primeiro grau, ainda.

Entretanto, o IRDR faz parte do microssistema, levando em consideração a existência de lacunas legislativas no novel ordenamento, considerar-se-á as regras de todas as espécies como uma regra comum, interseccionando quando for possível, criando um conglomerado de normas para o microssistema de formação de precedentes vinculantes.

Seguinte nessa linha, há a possibilidade, após a admissibilidade positiva, na decisão de afetação, com o pedido de informações para as varas de lo grau ou órgãos colegiados que já julgaram a matéria, que outros processos sejam afetados conjuntamente àquele que instaurou o incidente. Didier Jr. e Temer entendem que esses novos processos possam substituir ${ }^{38}$ o processo que suscitou o incidente e serviu de base para a instauração, posição um tanto inadequada, pelo entendimento de o requerente continua durante todo o incidente - ou enquanto tiver interesse - como parte deste, somente podendo o colegiado incluir mais processos ${ }^{39}$, mas não substituí-lo. No IAC e no incidente de arguição de inconstitucionalidade, há uma certa dificuldade na possibilidade de ampliação do recurso que representa a controvérsia para outros processos, apesar de não ser totalmente impossível.

No IAC, o cerne é a transferência da competência daquele processo - recurso, remessa necessária ou competência originária - para um órgão colegiado de composição maior, com o julgamento daquela questão controvertida juntamente à definição material daquele processo. Apesar de o resultado judicante gerar uma vinculação aos demais juízos, seja horizontalmente ou verticalmente, o julgamento é feito de maneira una, analisando no mesmo ato decisório, a questão suscitada para admissibilidade do incidente e, logo após a definição desta matéria, o julgamento do recurso ou outra espécie processual possível do incidente.

Dessa maneira, o próprio IAC está relacionado com o julgamento de um processo, com a análise da determinada demanda de maneira definitiva, apesar da possibilidade da mesma amplitude do contraditório de outras espécies do microssistema, com a manifestação de terceiros e da sociedade em geral, não há a pluralidade de julgamento, mesmo com o IAC fazendo parte do microssistema, há uma

38 Apesar de discordar de tal posição, é interessante analisar que Didier Jr. e Temer entendem que o IRDR proposto por um legitimado não é vinculado àquele processo, podendo o relator escolher outro processo depois da admissibilidade positiva. "Primeiramente, é preciso destacar que o relator não fica vinculado (i) ao processo de onde surja o pedido ou ofício para instauração do IRDR; (ii) à escolha realizada pela presidência do tribunal (em se admitindo que haverá tal escolha), 29 o que decorre também da aplicação do art. 1.036, § 4. do CPC/2015 (LGL \2015 \1656) ao IRDR, havendo, portanto, ampla margem de atuação do relator, que poderá selecionar os processos representativos.” DIDIER Jr. Fredie; TEMER, Sofia Orberg. A decisão de organização do incidente de resolução de demandas repetitivas: importância, conteúdo e o papel do regimento interno do tribunal. Revista de Processo | vol. 258/2016 | p. 257 - 278 | Ago / 2016. p. 266.

39 Essa possibilidade de inclusão de outros processos, apesar de não prevista legalmente, é interessante pela possibilidade de não se permitir, ao menos culturalmente, uma corrida por ser o autor do IRDR, como acontece nas class actions americanas, com o intuito de que o autor teria um privilégio sobre os demais processos e atuaria em favor da classe, contudo com uma gerência muito maior do que se discute. 
transferência de competência deste processo em específico, o que seria somente possível caso houvesse concomitantemente outro pedido de IAC sobre a mesma questão jurídica. Todavia, o correto e mais prudente seria a suspensão ${ }^{40}$ desse outro processo, com o posterior impacto e aplicabilidade da decisão definitiva do IAC primário. Ou, se o rito procedimental comportar e a abrangência do outro recurso for maior, julgá-los conjuntamente, apesar da dificuldade de tal hipótese.

No incidente de arguição de inconstitucionalidade, aquela questão jurídica somente recai sobre a possível inconstitucionalidade suscitada no processo, sem a possibilidade ou necessidade de ampliarse, para outras demandas. Há uma definição determinada sobre o que se discute - a dúvida sobre a inconstitucionalidade de dispositivo de lei - o que já determina a delimitação da discussão. Difícil entender a possibilidade de utilizar-se, no incidente de arguição de inconstitucionalidade, a suscitação de demais processos que contenham a mesma questão de direito, uma vez que a discussão é bem delineada pela própria relação dispositivo de lei e a sua compatibilidade com a Constituição Federal.

De certo modo, há uma conjuntura material mais específica neste instituto, necessitando que outro processo passasse pelo mesmo crivo da turma, com o mesmo trâmite, quase que simultaneamente.

\section{Aspectos conclusivos}

Não há no ordenamento processual vigente qualquer menção sobre aspectos objetivos e criteriosos para a escolha do processo representativo da controvérsia, com a competência, em todos os institutos, podendo ser exercida de modo discricionário pelo Poder Judiciário.

Nos institutos que outros legitimados podem ser suscitante, a escolha passa também pelas partes e pela sociedade, o que de certa maneira possibilita um procedimento mais democrático e dialógico. Todavia, há a necessidade de fixação de critérios e devidos entendimentos nas decisões de afetação de determinados recursos, com a consequência de menor discricionariedade judicante para tal escolha.

Os processos ou recursos base para o julgamento por amostragem em qualquer dos institutos formadores de precedentes vinculantes tem uma importância abismal, com o cuidado para que a escolha seja dentro de critérios cada vez mais específico, ainda que as partes e demais legitimados sejam também legitimados para a suscitação, o que importa em entendermos como ausente de escolha pelo Judiciário dos processos representativos da controvérsia, contudo há, ainda, a possibilidade de ampliação dos processos para outros que possam melhorar e contribuir com a argumentação jurídica, com a devida abrangência que o próprio CPC/2015 insere como necessária.

\section{Referências}

ATAÍDE JR, Jaldemiro Rodrigues de. As demandas de massa e o projeto de novo código de processo civil. In FREIRE, Alexandre at. Novas tendências do processo civil. Salvador: Jus Podivm, 2014.

BUENO, Cassio Scarpinella. Novo Código de Processo Civil anotado. 2a. Ed. São Paulo: Saraiva, 2016.

CABRAL, Antônio do Passo. A escolha das causa-piloto no incidente de resolução de demandas repetitivas. Revista de Processo. v. 231, Maio/2014.

CÂMARA, Freitas, A. (01/2017). O Novo Processo Civil Brasileiro, $3^{a}$ edição. [Minha Biblioteca]. Retirado de https://integrada.minhabiblioteca.com.br/\#/books/9788597009941/

CAMBI, Eduardo. FOGAÇA, Mateus Vargas. Sistema dos precedentes judiciais obrigatórios no novo código de processo civil. Precedentes. Organizadores: DIDIER JR., Fredie; CUNHA, Leonardo

40 Há quem julgue não ser cabível a suspensão de IAC, contudo seria, no mínimo, incongruente dentro do microssistema. Madruga, Mouzalas e Terceiro Neto concordam com a possibilidade de suspensão: "julgado o incidente, será vinculante o precedente, inclusive para os processos que ficaram sobrestados e também para os futuros, que venham a ser formados.” MADRUGA, Eduardo; MOUZALAS, Rinaldo; TERCEIRO NETO, João Otávio. Processo Civil Volume Único. 8a. ed. revisada, ampliada e atualizada. Salvador, Ed. JusPodivm, 2016. p. 935. 
Carneiro da; MACEDO, Lucas Buril de; ATAIDE JR, Jaldemiro Rodrigues de. Editora JusPodivm, Salvador, 2015.

CROSS, Rupert; HARRIS, J. W. Precedent in English Law. 4.ed. Oxford: Oxford University Press, 2004.

CUNHA, Leonardo José Carneiro da. Anotações sobre o incidente de resolução de demandas repetitivas previsto no projeto do novo Código de Processo Civil. Revista de Processo. São Paulo: Editora RT, março 2011,

CUNHA, Leonardo José Carneiro da; DIDIER JR., Fredie. Curso de direito processual civil. Meios de impugnação às decisões judiciais e processo nos tribunais. 13aㅡ ed. Salvador: JusPodivm, 2016.

DIDIER JR., Fredie; ZANETI JR., Hermes. Ações coletivas e o incidente de julgamento de casos repetitivos - espécies de processo coletivo no Direito brasileiro: aproximações e distinções. Revista de Processo | vol. 256/2016 | p. 209 - 218 | Jun / 2016.

DIDIER Jr. Fredie; TEMER, Sofia Orberg. A decisão de organização do incidente de resolução de demandas repetitivas: importância, conteúdo e o papel do regimento interno do tribunal. Revista de Processo | vol. 258/2016 | p. 257 - 278 | Ago / 2016.

FREIRE, Alexandre; SCHMITZ, Leonard Ziesemer; STRECK, Lenio Luiz. Comentários ao art. 948. STRECK, Lenio. Comentários ao código de Processo Civil, 11ª edição. Saraiva, 3/2016. [Minha Biblioteca]. Retirado de https://integrada.minhabiblioteca.com.br/\#/books/9788502635609/

FREIRE, Alexandre. Comentário ao art. 1.036. CABRAL, Passo, A. D., CRAMER, (orgs.), R. (06/2016). Comentários ao Novo Código de Processo Civil, 2a edição. [Minha Biblioteca]. Retirado de https://integrada.minhabiblioteca.com.br/\#/books/9788530971441/

LAMY, Eduardo de Avelar; TEMER, Sofia Orberg. A representatividade adequada na tutela de direitos individuais homogêneos. GRINOVER, Ada Pellegrini et al. (Coord.) Processo coletivo: do surgimento à atualidade. São Paulo: Revista dos Tribunais, 2014.

LEMOS, Vinicius Silva. Incidente de assunção de competência. Da conceituação à procedimentalidade. la. Ed. Jus Podivm. Salvador

LIMA, Tiago Asfor Rocha. Precedentes judiciais civis no Brasil. São Paulo, Ed. Saraiva. 2013.

MADRUGA, Eduardo; MOUZALAS, Rinaldo; TERCEIRO NETO, João Otávio. Processo Civil Volume Único. 8a. ed. revisada, ampliada e atualizada. Salvador, Ed. JusPodivm, 2016.

MANCUSO, Rodolfo de Camargo. Incidente de resolução de demandas repetitivas: a luta contra a dispersão jurisprudencial excessiva.la. ed. São Paulo: Ed. RT. 2016.

MARINONI, Luiz Guilherme. O “problema” do incidente de resolução de demandas repetitivas e dos recursos extraordinário e especial repetitivos. Revista de Processo. vol. 249. ano 40. p. 399-419. São Paulo: Ed. RT, nov. 2015.

MARINONI, Luiz Guilherme; MITIDIERO, Daniel. Repercussão geral no recurso extraordinário. 2. Ed. São Paulo: Editora RT, 2008.

MARINONI, Luiz Guilherme; ARENHART, Sérgio cruz; MITIDIERO, Daniel. Novo Curso de Processo Civil: Tutela dos Direitos Mediante Procedimento Comum. São Paulo: Revista dos Tribunais, v.2. 2015.

MOREIRA, José Carlos Barbosa. O novo processo civil brasileiro: exposição sistemática do procedimento. 27. ed, Ed. Forense, 2008.

NERY JR, Nelson; NERY, Rosa Maria de Andrade. Código de Processo Civil Comentado. 16a. Ed. São Paulo. RT. 2016.

NUNES, Dierle; BAHIA, Alexandre; PEDRON, Flávio Quinaud. Comentários ao art. 1.030. STRECK, Lenio. Comentários ao código de Processo Civil, 11ª edição.. Saraiva, 3/2016. [Minha Biblioteca]. Retirado de https://integrada.minhabiblioteca.com.br/\#/books/9788502635609/ 
PITTA, Fernanda. Comentário ao art. 1.036. Novo Código de Processo Civil Comentado - Tomo III (art. 771 ao art. 1.072). Orgs: RIBEIRO, Sergio Luiz Almeida; GOUVEIA FILHO, Roberto Pinheiro Campos; PANTALEÃO, Izabel Cristina; GOUVEIA, Lucio Grassi de. Ed. Lualri, São Paulo, 2017.

RIBEIRO, Cristiana Hamdar. A lei dos recursos repetitivos e os princípios do direito processual civil brasileiro. Revista Eletrônica de Direito Processual - Volume V, n. 5. 2010.

SCHELEDER, Adriana Fasolo Pilati. A inconstitucionalidade da aplicação do incidente de resolução de demandas repetitivas nos juizados especiais. Florianópolis, SC, 2015. 410 p. Tese (doutorado).

Universidade Federal de Santa Catarina, Centro de Ciências Jurídicas. Programa de Pós-Graduação em Direito.

STRECK, Lênio Luiz. Súmulas, vaguezas e ambiguidades: necessitamos de uma "teoria geral dos precedentes"? Direitos Fundamentais \& Justiça nº 5 - out./DEZ. 2008.

TALAMINI, Eduardo. Novos Aspectos da Jurisdição Constitucional Brasileira: Repercussão Geral, Força Vinculante, Modulação dos Efeitos do Controle de Constitucionalidade e Alargamento do Objeto do Controle Direto, São Paulo, Tese de Livre-Docência, USP, 2008.

TEIXEIRA, Guilherme Puchalski. Incidente de resolução de demandas repetitivas: projeções em torno de sua eficiência. Revista eletrônica de direito processual - REDP. Volume 16. Julho a dezembro de 2015.

TEMER, Sofia Orberg. Incidente de resolução de demandas repetitivas. la. Ed. Jus Podivm, 2016.

THEODORO JR., Humberto. Regime das demandas repetitivas no novo código de processo civil. Coleção Novo CPC - Doutrina Selecionada - v.6 - Processo nos Tribunais e Meios de Impugnação às Decisões Judiciais. Organizadores: DIDIER JR., Fredie; FREIRE, Alexandre; MACEDO, Lucas Buril de; PEIXOTO, Ravi. 2a. Ed. JusPodivm, Salvador, 2016. 